\title{
Mapping Predictive Maintenance in SCADA-Based Industries: A literature review
}

\author{
E.H.E. Suryadarma* and T.J. Ai
}

\begin{abstract}
The purpose of this paper is to mapping and review what has been done on the topic of research on predictive maintenance in SCADA (Supervisory Control and Data Acquisition) based industries. In the research area of predictive maintenance, various methods for predicting damage or time to failure of a machine have been proposed and applied in various industries. This paper systematically categorizes predictive maintenance in SCADA-based industries research based on industry classifications according to ISIC (International Standard Industrial Classification of All Economic Activities). Furthermore, the research scope is explored its connection to the topics of Internet of Things (IoT), Artificial Intelligence (AI), Machine Learning (ML), and Supervisory Control and Data Acquisition (SCADA). It is found that $81.5 \%$ of the research was conducted on the electricity, gas, steam, and air conditioning supply industries, $11.1 \%$ of research was conducted on the mining and quarrying industry, and $7.4 \%$ of the research conducted in the manufacturing industry. It is also found that $85.2 \%$ of studies used AI and ML, $18.5 \%$ of the studies used IoT and $18.5 \%$ of research used AI/ML and IoT technology together.
\end{abstract}

Keywords: predictive maintenance, Supervisory Control and Data Acquisition (SCADA), Internet of Things (IoT), Artificial Intelligence (AI), Machine Learning (ML).

Article Info: Received April 10, 2021; Revised May 14, 2021; Accepted July 1, 2021.

\section{INTRODUCTION}

A lean enterprise focuses on its effort to minimize waste on its operation (Besterfield, 2013). Waste, in general, can be classified into eight categories, which are: overproduction, waiting (time on hand), transportation or conveyance, defects, excess inventory, unnecessary movement, over-processing or incorrect processing, and unused employee creativity (Liker \& Meier, 2006). One possible effort for manufacturers to minimize waste is to maintain their machines since at least one type of waste occurs whenever a machine is unavailable. For example, defective products (defects) and material waiting in front of the machine (waiting) are two types of waste as the effects of a broken machine. To sustain the machine availability, therefore, a maintenance management program is essential to conduct.
There are two types of maintenance management programs in traditional maintenance, which are called run-to-failure and preventive maintenance. In order, the run-to-failure type is straightforward, which is repairing a machine whenever it is broken. And then, preventive maintenance is a technique based on the time a machine is used (Mobley, 2002). For example, a machine will usually be damaged after being used for seven months. Then based on preventive maintenance techniques, a machine will be maintained after six months of operation. Preventive maintenance consists of regularly scheduled inspection, adjustments, cleaning, lubrication, parts replacement, calibration, and repair of components and equipment. Preventive maintenance is also referred to as time-driven or interval-based maintenance, and it is performed without regard to equipment conditions (NASA, 2000). Unlike traditional maintenance techniques that rely on intuition, predictive

E.H.E. Suryadarma* is with the Department of Industrial Engineering, Universitas Atma Jaya Yogyakarta, Indonesia (email: engelbert.harsandi@uajy.ac.id).

* Corresponding author 
maintenance relies on routine monitoring data of actual mechanical conditions, efficiency, and other indicators. It is conducted to ensure maximum intervals between repairs and minimize unscheduled engine failures (Mobley, 2002).

Predictive maintenance usually requires an extensive data set from monitoring a production line continuously. SCADA (Supervisory Control and Data Acquisition) is a technology that can answer these challenges. SCADA is a technology that allows us to collect data from one or more production facilities that are far enough away and can send instructions to control the facility (Boyer, 2004). Data from SCADA is used in one of the following ways to determine the condition of the machine. For example, trend analysis, pattern recognition, data comparison, test against limits and ranges, and statistical process analysis (NASA, 2000). When data from SCADA is needed for analysis in a control center that is far from the production facility, it can be developed through the Internet of Things (IoT) concept. In the IoT concept, every object or machine can communicate with other objects via the internet (AlTurjman, 2017).

Understanding and processing many data requires automated data processing technology or Artificial Intelligence. Artificial Intelligence (AI) emphasizes creating machine intelligence with human functions (AlSahaf et al., 2019). And then, Machine Learning (ML) is a continuation of AI that emphasizes learning about pattern recognition and computational learning. The key is to use computers to learn from data and can make decisions with minimal human intervention (Hwang \& Chen, 2017). We can use the technology of AI/ML to develop a predictive maintenance system, so AI/ML can learn from data SCADA to predict machine fault. The taxonomy of ML is generally divided into supervised learning and unsupervised learning (Stetco et al., 2018). In Supervised learning, there is training data that will be used to determine decisions when new data appears, while unsupervised learning without training data (Shalev-Shwartz \& Ben-David, 2014). There are several algorithms for supervised learning such as Regression, Classification, Decision Trees, Bayesian Network, then for unsupervised learning such as Association Analysis, Clustering, Dimensionality Reduction, Artificial Neural Networks (Hwang \& Chen, 2017).

This paper will comprehensively discuss research related to predictive maintenance and SCADA following mapping presented in Figure 1. It aims to provide a comprehensive insight into some of the research that has been done with this theme. This paper is written from several papers obtained from the Scopus ${ }^{\circledR}$ database about predictive maintenance and SCADA. In Section 2, we will explain the method of literature review and grouping based on industry classification. Section 3 is about the classification based on machine learning methods and IoT. In section 4, a discussion of this review's findings is presented. Furthermore, we propose predictive maintenance with a combination of supervised and unsupervised machine learning. The last section is the conclusion of this paper.

\section{METHODS AND INDUSTRY \\ CLASSIFICATION}

We followed the steps illustrated in Figure 2 for conducting a literature review on predictive maintenance and SCADA. Initially, we started with searching for articles that contained "predictive maintenance" and "SCADA" keywords on the Scopus ${ }^{\circledR}$ database. In total, it is found 42 articles, in which the earliest article had been written in 2000 . Whenever the number of articles per year is mapped as a bar chart presented in Figure 3, the increasing trend of articles on these keywords is clearly shown.

After that, the papers are categorized based on the industrial classification of ISIC (International Standard

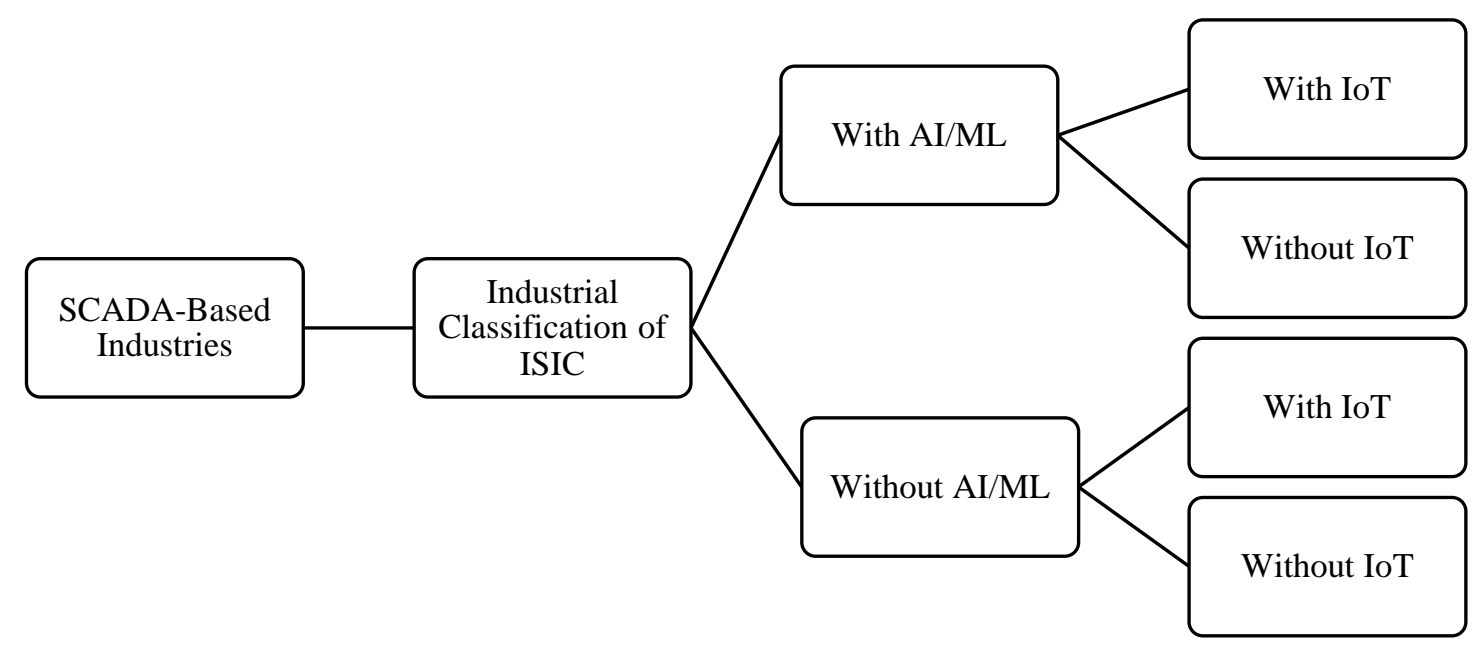

Figure 1. SCADA-Based Industries Mapping. 


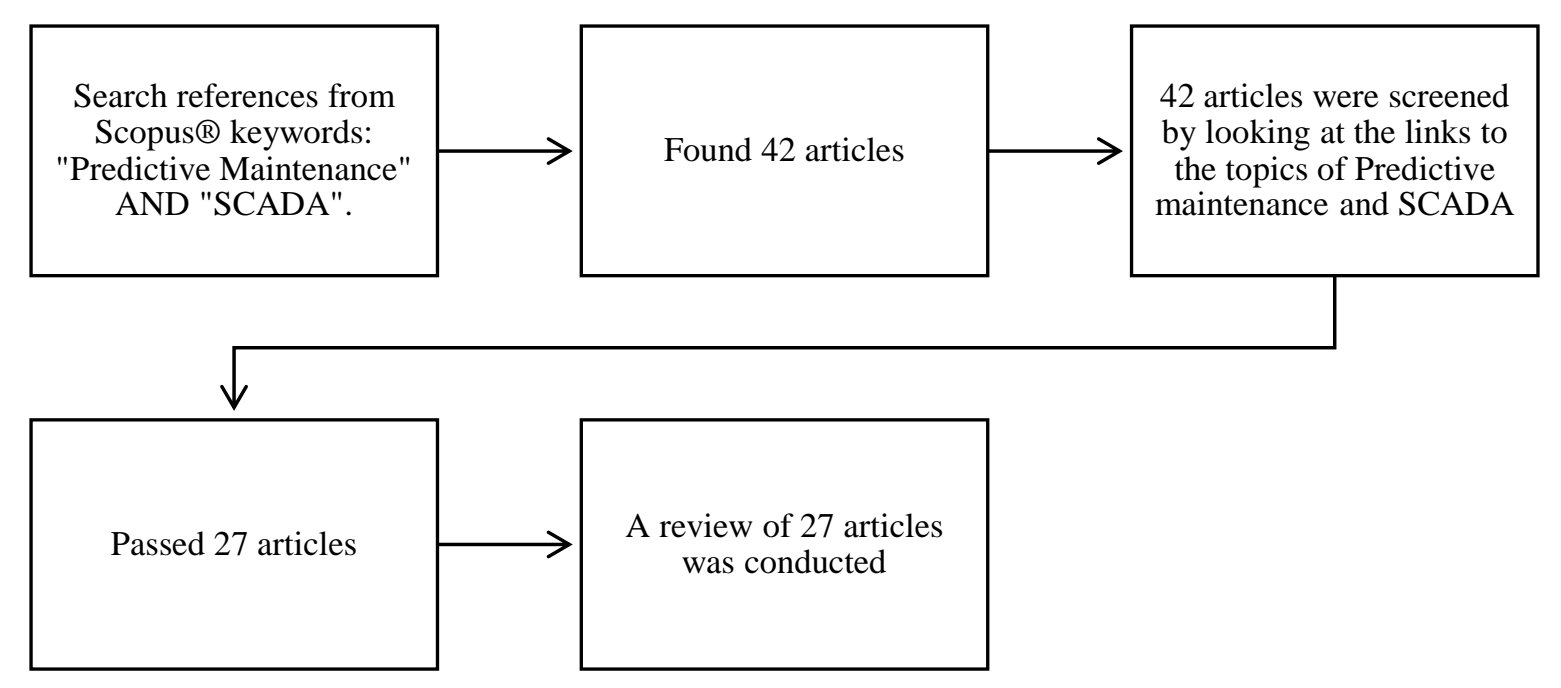

Figure.2 Steps to search for articles

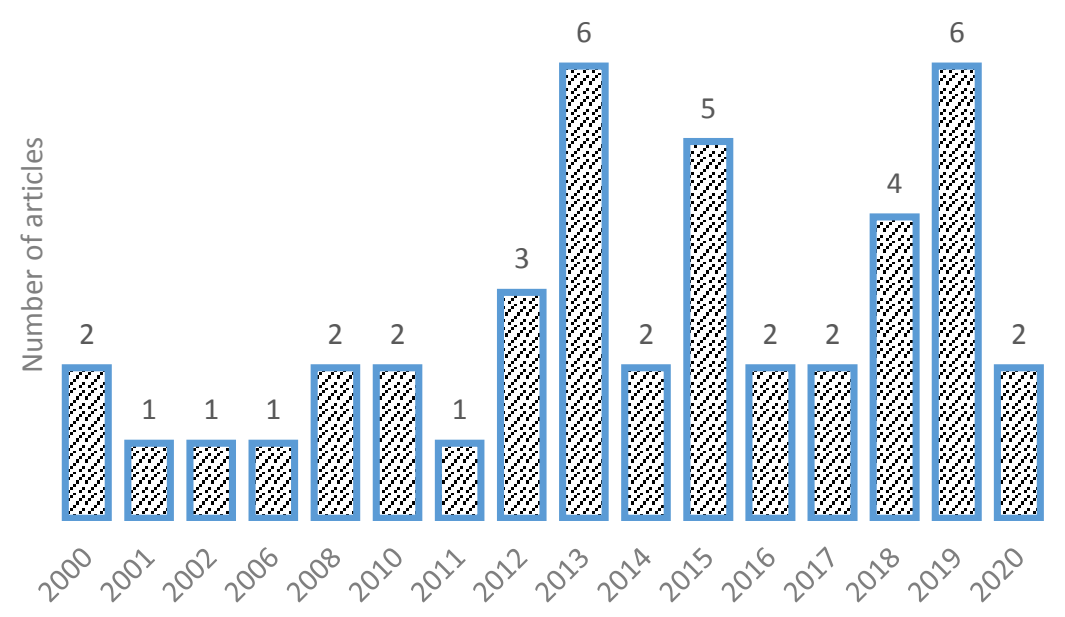

Figure 3. Number of articles base on publication year

Industrial Classification of All Economic Activities), which consists of 21 sections (UN, 2008). The number of articles by industry category is presented in Table 1 . The majority of articles in this area were conducted in the electricity, gas, steam, and air conditioning supply industry, 29 articles or $49.2 \%$ of the articles. The second most was conducted in the other service activities industry, which is four articles or $6.8 \%$. Three articles, or $5.1 \%$, were in the area of mining and quarrying industry, while three articles or $5.1 \%$ were in the area of the manufacturing industry.

Furthermore, papers from each industry category will be discussed in more detail. Based on 21 sections according to ISIC, there are only seven industry categories that have discussions about predictive maintenance and SCADA. The seven categories are mining and quarrying; manufacturing; electricity, gas, steam, and air conditioning supply; water supply; sewerage, waste management, and remediation activities; construction; information and communication; other service activities.

\subsection{Electricity, gas, steam, and air conditioning supply}

There are several predictive maintenances with SCADA papers on the industry category of electricity, gas, steam, and air conditioning supply. Moleda et al. (2020) proposed a predictive maintenance system for coal-fired power plant boiler pumps with SCADA and IoT data. Nisi et al. (2019) and Renga et al. (2020) built a prognostic-diagnostic model based on several years of SCADA data from the electricity distribution network. Gigoni et al. (2019) proposed predictive maintenance on wind turbines with SCADA data. Almost similar to Gigoni et al. (2019), the SCADA data has been proposed 
E.H.E Suryadarma and T.J. Ai

Table 1 . Number of articles by industry category

\begin{tabular}{|c|l|c|}
\hline Section & \multicolumn{1}{|c|}{ Description } & Quantity \\
\hline A & Agriculture, forestry, and fishing & 3 \\
\hline B & Mining and quarrying & 3 \\
\hline C & Manufacturing & 29 \\
\hline D & Electricity, gas, steam, and air conditioning supply & 1 \\
\hline E & Water supply; sewerage, waste management and remediation activities & 1 \\
\hline F & Construction & \\
\hline G & Wholesale and retail trade; repair of motor vehicles and motorcycles & \\
\hline H & Transportation and storage & 1 \\
\hline I & Accommodation and food service activities & \\
\hline J & Information and communication & \\
\hline K & Financial and insurance activities & \\
\hline L & Real estate activities & \\
\hline M & Professional, scientific, and technical activities & \\
\hline N & Administrative and support service activities & \\
\hline O & Public administration and defense; compulsory social security & \\
\hline P & Education & \\
\hline Q & Human health and social work activities & \\
\hline R & Arts, entertainment, and recreation & \\
\hline S & Other service activities & \\
\hline T & Activities of households as employers; undifferentiated goods- and services- & \\
\hline U & Activities of extraterritorial organizations and bodies & \\
\hline
\end{tabular}

to be analyzed with statistical classification techniques for a better prediction (Colone et al., 2019; Leahy et al., 2018). The difference with Colone et al. (2019) and Leahy et al. (2018) proposed classification techniques, De La Hermosa González-Carrato et al. (2013) proposed a new algorithm for conducting predictive maintenance on wind turbines. Still, in research on wind turbines, Bangalore \& Tjernberg (2015) studied detection of gearbox bearing fault in wind turbines with a neural network approach, which was a continuation of research about a prediction of wind turbine disturbance with neural network algorithms and SCADA data (Bangalore \& Tjernberg, 2013). Another similar case with research conducted by Bangalore \& Tjernberg (2013), Godwin et al. (2013) studied SCADA data classification used to predict system faults in the control system. In the same year, Godwin \& Matthews (2013) studied SCADA data classification used to predict system faults in wind turbines.

Several papers on the industry category of electricity, gas, steam, and air conditioning supply also conduct research in a case study. Zhao et al. (2017) took the case study to calculate the remaining useful life (RUL) of wind turbines in China using SCADA data. Instead of using data from a single wind turbine, there was a proposal for comparing behavior between wind turbines using SCADA data to predict damage (Lebranchu et al., 2016). To explain the ability of SCADA as a controller system, Montague (2015) conducted research on the Control 50MW hydropower plant at Columbia with SCADA. In contrast to Montague, who conducted research in hydropower plants, Carter (2008) conducted research in coal power plants. He studied the efficiency of the start-up process in coal power plants while Tinham (2008) evaluated the temperature in chemical reactors for predictive maintenance with a SCADA system. In addition to research in hydropower plants, coal power plants, and nuclear power plants, Olivencia Polo et al. (2010) conducted research to predict the failure of a photovoltaic system by comparing real production on SCADA data with theoretical production results. Sánchez \& Couso (2012) conducted research about wind power plants about the use of SSA (singular spectral analysis) for predictive maintenance of windmills in Spanish wind turbine fields. Lebranchu et al. (2015) explored SCADA data to determine the health of wind turbines. Still, Zhao et al. (2013) studied degradation assessment on the wind turbine drive system around the wind turbine. Perez (2010) proposed fatigue calculation techniques using SCADA data as a basis for predictive maintenance for wind turbines. De La Hermosa Gonzalez-Carrato et al. (2012) conducted research with a complete scope, i.e., increased RAMS (reliability, availability, maintainability, safety) wind turbine with SCADA (Sound and vibration data).

In addition to the case study topics, several papers on the industry category of electricity, gas, steam, and air conditioning supply also conducted research in the form of a literature review. Tautz-Weinert \& Watson (2017) studied the literature review using SCADA data to monitor wind turbine conditions.

Not only developed in the power plant industry, but some researchers also researched power grids, such as predictive maintenance on generator motors and power distribution equipment with SCADA (Ignat et al., 2012). 
Table 2. Distribution of research by industry category

\begin{tabular}{|l|l|}
\hline \multicolumn{1}{|c|}{ Category } & \multicolumn{1}{|c|}{ Number of articles } \\
\hline Electricity, gas, steam, and air conditioning supply & 22 \\
\hline Mining and quarrying & 3 \\
\hline Manufacturing & 2 \\
\hline
\end{tabular}

Gonzalez et al. (2014) proposed predicting the lifespan of the capacitive voltage transformer by analyzing the isolation system. Singh et al. (2013) proposed a monitoring system in the Smart Grid network that intervenes between SCADA and Phasor Measurement Units (PMU). PMU is a device for estimating the phase angle and the amount of electricity in the electricity network used for synchronization. Toporek \& Hutchings (2011) proposed a method for collecting process failure files from historian non-SCADA. Khatib et al. (2000) proposed a blueprint for an internet-based power system information network. Based on the development in the industry, Carter (2006) predicted that using SCADA in the power industry is continuously growing at least at the rate of $4 \%$ until 2009.

\subsection{Other service activities}

Several papers discuss general things about SCADA. Hagner and Bujak (2016) discussed the terms and benefits of an asset is connected to the SCADA system. Richard (2015) discussed some examples of using SCADA. While Waterbury (2001) discussed the evaluation and urgency of investment in the automation process. Schafer (2000) proposed optimizing predictive maintenance with the SCADA automated system.

\subsection{Mining and quarrying}

There is some research on the mining and quarrying industry. Rensburg (2019a) and Rensburg (2019b) proposed the concept of applying AI to the ESP (Electrical Submersible Pump) by detecting, scanning, and recovering abnormal conditions in ESP. They also presented a method for detecting anomalies using AI technology for autonomous surveillance systems on ESP. Similar to research conducted by Rensburg, who researched oil mines, Mazur et al. (2014) conducted a study in coal mines. He proposed the application of predictive maintenance in the mining industry based on vibration data.

\subsection{Manufacturing}

Like research in the mining and quarrying industry area, there are also three studies in the manufacturing industry area. Some research on the manufacturing industry proposed a new system-level anomaly prediction framework in smart manufacturing by mining anomaly dependency graphs from sensor data (Wang et al., 2018). Kiangala and Wang (2018) proposed the basic concept of industry 4.0 in bottling SMEs. Grosch and Bilot (2002) proposed the design of a digital nervous system for water management and wastewater facilities.
2.5. Water supply, sewerage, waste management, and remediation activities

There is only one research in the water supply, sewerage, waste management, and remediation activities. Nuñez et al. (2019) wrote a paper about the use of the SCADA system in the desalination process.

\subsection{Construction}

The same as research in the water supply, sewerage, waste management, and remediation activities, there is only one paper in the construction industry. Berardis and Donisi (2018) proposed real-time monitoring of structural conditions with SCADA on the Turkish Osmagazi.

\subsection{Information and communication}

The same as research in the water supply, sewerage, waste management and remediation activities, and construction industry, there is only one paper in the information and communication industry. Ajami and Gosine (2015) proposed a digital bus concept with DCS (distributed control system).

After reviewing 42 papers carefully, 15 papers were not relevant to the topic of SCADA and predictive maintenance. Some of the paper only discussed the SCADA as data collection, the benefit of using a SCADA system (Hagner and Bujak, 2016; Montague, 2015; Richard, 2015; Lebranchu et al., 2015; Ajami and Gosine, 2015; Carter, 2008; Berardis and Donisi, 2018; Carter, 2006; Khatib et al., 2000; Nuñez et al., 2019). Meanwhile, some other papers only discussed predictive maintenance without using SCADA data (Gonzalez et al., 2014; Toporek and Hutchings, 2011; Grosch and Bilot, 2002). Moreover, some other papers discussed the management of automated systems (Waterbury, 2011; Schafer, 2000). Therefore, only 27 articles are relevant to the topic of SCADA and predictive maintenance. The revised number of articles by industry category is presented in Table 2, and the further review of these articles is presented in Section 3.

\section{MACHINE LEARNING AND IoT CLASSIFICATION}

In this section 3, the paper will be classified based on machine learning techniques and the use of IoT. Based on Table 2, 81.48\% of the research was conducted on the electricity, gas, steam, and air conditioning supply industries, $11.11 \%$ of research was conducted on the mining and quarrying industry, and $7.41 \%$ of the research conducted in the manufacturing industry. Based on Table 3, $14.81 \%$ of research did not discuss artificial intelligence (AI) or machine learning (ML), $85.19 \%$ of studies discussed AI and ML, $81.48 \%$ of 
E.H.E Suryadarma and T.J. Ai

studies did not discuss IoT, $18.52 \%$ of the studies discussed IoT, and only 5 of 27 research used AI/ML and IoT technology together.
Furthermore, the research article will be mapped based on the learning style and algorithm used. Fifteen papers used a supervised learning style, seven papers

Table 3. Distribution of research based on the use of AI / ML and IoT

\begin{tabular}{|c|c|c|c|c|}
\hline \multirow[t]{2}{*}{ Category } & \multicolumn{2}{|c|}{ Without AI/ML } & \multicolumn{2}{|c|}{ With AI/ML } \\
\hline & Without IoT & With IoT & Without IoT & With IoT \\
\hline Electric power & \begin{tabular}{ll}
\multicolumn{2}{l}{ Tautz-Weinert } \\
\& $\quad$ Watson \\
$(2017)$; \\
al. & (2013); \\
Perez & (2010); \\
Tinham & (2008).
\end{tabular} & - & $\begin{array}{l}\text { Renga et al. (2020); Gigoni et } \\
\text { al. (2019); Nisi et al. (2019); } \\
\text { Colone et al. (2019); Leahy et } \\
\text { al. (2018); Zhao et al. (2017); } \\
\text { Lebranchu et al. (2016); } \\
\text { Bangalore \& Tjernberg } \\
\text { (2015); Bangalore \& } \\
\text { Tjernberg (2013); Singh et al. } \\
\text { (2013); De La Hermosa } \\
\text { González-Carrato et al. } \\
\text { (2013); Godwin \& Matthews } \\
\text { (2013); Godwin et al. (2013); } \\
\text { Ignat et al. (2012). }\end{array}$ & $\begin{array}{l}\text { Moleda et al. (2020); } \\
\text { Olivencia Polo et al. } \\
(2010) \text {. }\end{array}$ \\
\hline Manufacturing & - & - & Wang et al. (2018) & $\begin{array}{lll}\begin{array}{l}\text { Kiangala } \\
(2018)\end{array} & \& & \text { Wang } \\
\end{array}$ \\
\hline Mining & - & - & Mazur et al. (2014) & $\begin{array}{l}\text { Rensburg (2019a); } \\
\text { Rensburg (2019b) }\end{array}$ \\
\hline
\end{tabular}

Table 4. Mapping research articles based on the learning style and algorithm used

\begin{tabular}{|c|c|c|c|}
\hline Learning Style & Algorithm Class & Algorithm Name & Papers \\
\hline \multirow[t]{9}{*}{ Supervised } & Regression & Linear & $\begin{array}{l}\text { Moleda et al. (2020); Lebranchu et al. } \\
\text { (2016); Mazur et al. (2014); Olivencia } \\
\text { Polo et al. (2010) }\end{array}$ \\
\hline & \multirow[t]{4}{*}{ Classification } & Ripper & $\begin{array}{l}\text { Godwin \& Matthews (2013); Godwin } \\
\text { et al. (2013) }\end{array}$ \\
\hline & & rule-based classification & $\begin{array}{l}\text { Kiangala \& Wang (2018); Singh et al. } \\
\text { (2013) }\end{array}$ \\
\hline & & $\begin{array}{l}\text { support vector machine } \\
(\mathrm{SVM})\end{array}$ & Zhao et al. (2017) \\
\hline & & $\begin{array}{l}\text { SVM and decision tree } \\
\text { classifiers }\end{array}$ & Leahy et al. (2018) \\
\hline & \multirow[t]{4}{*}{ Other } & dependency graph & Wang et al. (2018) \\
\hline & & Fuzzy logic & Sánchez \& Couso (2012) \\
\hline & & not specify & Ignat et al. (2012) \\
\hline & & wavelet decomposition & $\begin{array}{l}\text { De La Hermosa Gonzalez-Carrato et } \\
\text { al. (2012); De La Hermosa González- } \\
\text { Carrato et al. (2013) }\end{array}$ \\
\hline \multirow[t]{3}{*}{ Unsupervised } & Association analysis & Association rules & Renga et al. (2020); (Nisi et al. (2019) \\
\hline & $\begin{array}{l}\text { Artificial neural } \\
\text { network }\end{array}$ & Neural Network & $\begin{array}{l}\text { Rensburg (2019a); Rensburg (2019b); } \\
\text { Bangalore \& Tjernberg (2013); } \\
\text { Bangalore \& Tjernberg (2015) }\end{array}$ \\
\hline & Combinate & $\begin{array}{l}\text { Neural Network \& K- } \\
\text { means }\end{array}$ & Gigoni et al. (2019) \\
\hline Combinate & $\begin{array}{l}\text { Bayesian network and } \\
\text { Artificial neural } \\
\text { network }\end{array}$ & $\begin{array}{l}\text { Naïve Bayes classifier } \\
\text { and Neural Network }\end{array}$ & Colone et al. (2019) \\
\hline
\end{tabular}


Table 4. (continued)

\begin{tabular}{|l|l|l|l|}
\hline Learning Style & \multicolumn{1}{|c|}{ Algorithm Class } & \multicolumn{1}{|c|}{ Algorithm Name } & \multicolumn{1}{c|}{ Papers } \\
\hline \multirow{2}{*}{ not specify } & not specify & fatigue counter & Perez (2010) \\
\cline { 3 - 4 } & & spectral kurtosis filtering & Zhao et al. (2013) \\
\cline { 3 - 4 } & & temperature graph & Tinham (2008) \\
\cline { 3 - 4 } & & not specify & Tautz-Weinert \& Watson (2017) \\
\hline
\end{tabular}

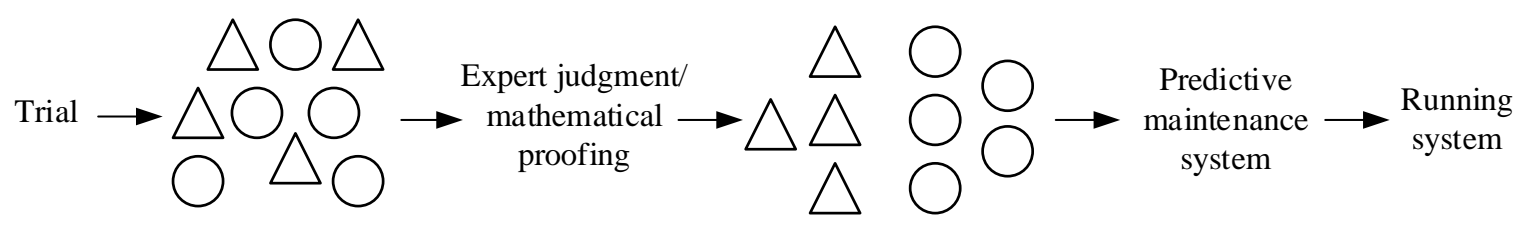

Trial data

Training data

Figure 4. Predictive maintenance with supervised machine learning

used an unsupervised learning style, one paper used a combination of supervised and unsupervised, and four papers did not show a specific learning style. Detail mapping is shown in Table 4.

\section{DISCUSSION}

The process of analyzing data to predict the best time to do maintenance can also be done manually by viewing data regularly by maintenance department personnel. However, this method is less efficient because it requires considerable human resources, and the reliability of predictive maintenance systems manually is very dependent on the operator's ability. However, now, information technology has developed rapidly, resulting in the SCADA system and Machine Learning techniques. In general, SCADA in predictive maintenance systems is used as a supplier of data or can be referred to as a source of big data. Then this data is used to predict the best time to do maintenance with machine learning techniques (Suryadarma et al., 2020).

The majority of papers $(55.55 \%)$ reviewed in this paper are using supervised machine learning. This trend occurs because predictive maintenance, in some cases/machinery/industry, is unique and requires expert judgment or even mathematical proofing. Supervised machine learning allows us to determine training data sets. The process of predictive maintenance with supervised machine learning can be illustrated in Figure 4.

Building a predictive maintenance system with supervised machine learning starts with a trial in the normal process. The next step is trial data collected (this step can be done with the help of the SCADA system). After the trial data is obtained, the next step is to analyze the data with expert judgment and mathematical proofing. This step aims to obtain appropriate training data to separate data that describes potential failures and data that describe the process going well. After the training data is obtained, it will be used to build a predictive maintenance system. Many choices of supervised machine learning methods, the choice depends on each case.

Moreover, there is no specific standard for choosing a machine learning method. After building a predictive maintenance system, the final step is to run the predictive maintenance system. Meanwhile, still paying attention to the PDCA (Plan Do Check and Action) cycle to conduct a review of the training data to remain relevant.

Another thing with supervised machine learning, unsupervised machine learning does not require training data. The process of predictive maintenance with unsupervised machine learning can be illustrated in Figure 5.

Building a predictive maintenance system with unsupervised machine learning also starts with a trial in the normal process and collects the trial data. If supervised machine learning after trial and data collection requires expert judgment or mathematical proofing to make training data, then unsupervised machine learning does not require that step. Nevertheless, after the trial, data collected can immediately build a predictive maintenance system. After building a predictive maintenance system, the final step is to run the predictive maintenance system. Unsupervised machine learning has simple steps but usually has a more complicated algorithm.

To get more accurate prediction results, we propose to use a combination of supervised and unsupervised machine learning. Supervised learning has the advantage of handling specific cases that require expert judgment. In fact, almost all predictive maintenance cases are specific. Unsupervised learning has advantages in terms of the ability to classify data without the need to make training data, and this is simpler than the supervised learning step. It can be said that unsupervised learning has the ability to learn from abstract things without having to be given "training" first. The proposed predictive maintenance process with combination machine learning can be illustrated in Figure 6. 


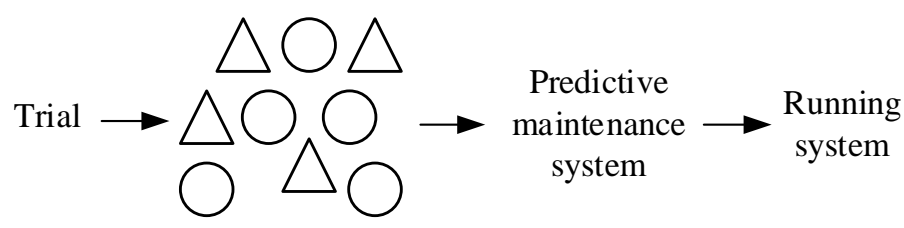

Trial data

Figure 5. Predictive maintenance with unsupervised machine learning

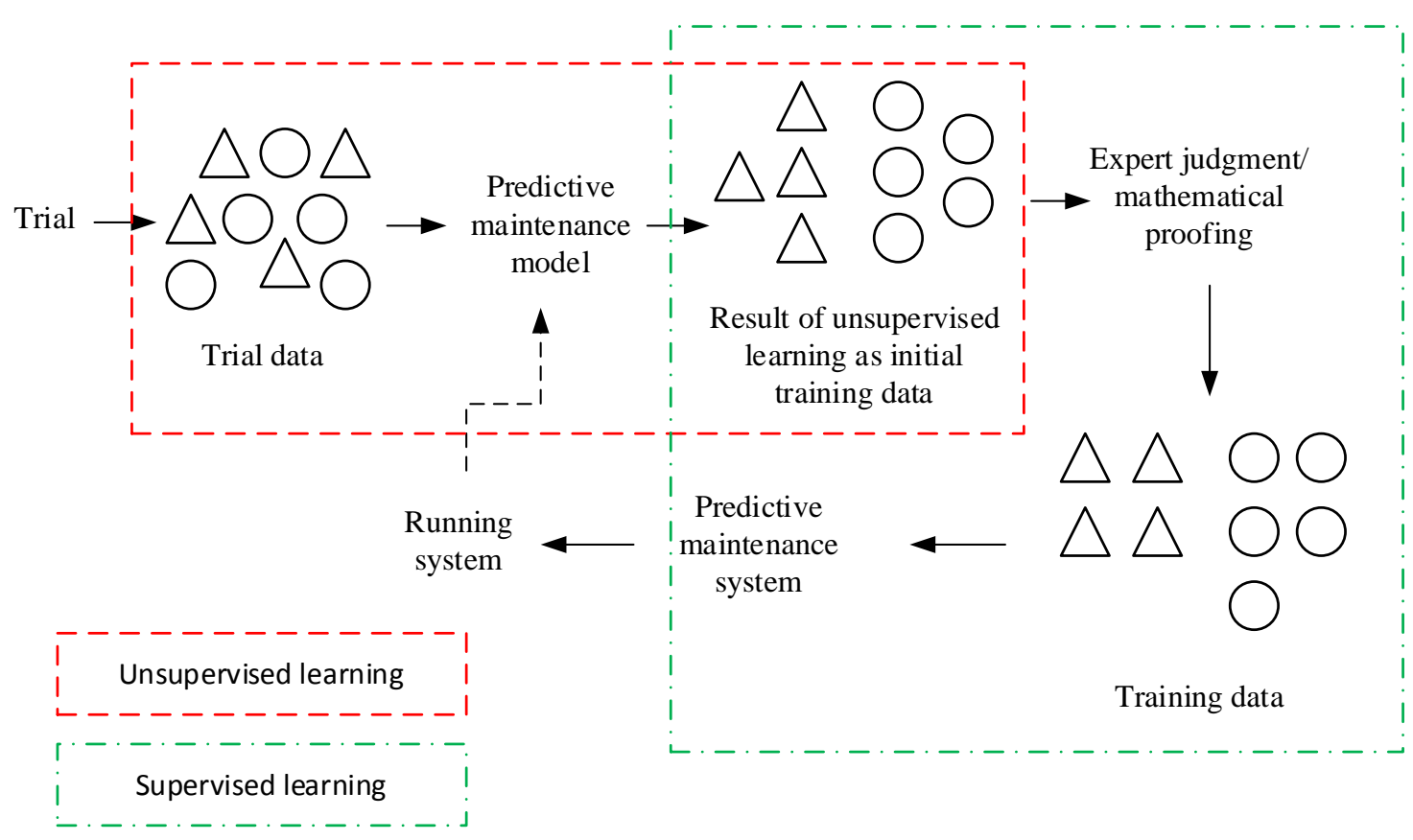

Figure 6. The proposed predictive maintenance process with combination machine learning

Building a predictive maintenance system with a combination of machine learning begins with unsupervised learning, followed by supervised learning. The first step is the same as the previous method, which is trial and data collection. The next step is an analysis using unsupervised machine learning, and the results are used as initial training data. The next step is followed by supervised machine learning, with expert judgment and mathematical proofing. Then it produces training data, which will be used as a basis for building a predictive maintenance system. The predictive maintenance system can be evaluated periodically using a data running system as an input analysis of unsupervised learning.

\section{CONCLUSION}

Research on Predictive Maintenance in industries that use the SCADA system is still limited. Based on the results of a reference search from Scopus ${ }^{\circledR}$ with the keyword: "Predictive Maintenance" AND "SCADA", only found 27 research papers that are relevant to this topic. Among the relevant research, $81.5 \%$ of the research was conducted on the electricity, gas, steam, and air conditioning supply industries, $11.1 \%$ of research was conducted on the mining and quarrying industry, $7.4 \%$ of the research conducted on the manufacturing industry. It is also found that $85.2 \%$ of studies discussed AI and ML, $18.5 \%$ of the studies discussed IoT, and $18.5 \%$ of research used AI/ML and IoT technology together. Research in the manufacturing and mining industries is still very little. This gap can be filled with research that can contribute to the manufacturing and mining industries, specifically covering SCADA and Predictive maintenance. The challenge of implementing predictive maintenance and SCADA systems is the investment cost of an integrated controller and the readiness of the company's human resources. However, using this technique will significantly impact reducing machine downtime to increase the efficiency of the production process. Also, the use of the SCADA system will make it easier for management to manage the production process because it will get accurate data in real-time. Likewise, the workers will focus more on targets, which will make the work rhythm more regular. The comprehensive comparison of IoT, AI/ML techniques in SCADABased Industries shown in Table 5. 
This paper aims to map and review research on predictive maintenance in SCADA (Supervisory Control and Data Acquisition) based industries is already done. In the future, there will be many open source SCADA systems developed so that this technology will be cheaper and can be used in factories widely. Therefore, research on predictive maintenance and SCADA is needed, especially for open source systems. In addition, there are still many algorithms that have not been used in the development of predictive maintenance in the SCADA industry.

Researchers can then use the AI / ML algorithm or even can combine several algorithms to obtain better prediction results. In addition, using IoT is also expected to appear in many subsequent studies so that the Predictive Maintenance system can be monitored from a distance. In addition, a complete mapping of using machine learning, IoT, and industry categories will support further research, shown in Table 6.

Table 5. The comprehensive comparison of IoT, AI/ML techniques in SCADA-Based Industries

\begin{tabular}{|l|l|l|l|}
\hline SCADA-Based Industries Research & With IoT & Without IoT \\
\cline { 3 - 4 } & $\begin{array}{l}\text { It can be controlled remotely, } \\
\text { suitable for industries that have } \\
\text { facilities in several distant } \\
\text { places. }\end{array}$ & $\begin{array}{l}\text { Communication by wire, suitable } \\
\text { for industries that have centralized } \\
\text { facilities. }\end{array}$ \\
\hline With & $\begin{array}{l}\text { Machine-assisted } \\
\text { Aecision-making makes } \\
\text { it easier for humans to } \\
\text { make the best decisions } \\
\text { with little human } \\
\text { interference. Suitable for } \\
\text { complex systems. }\end{array}$ & $\begin{array}{l}\text { Machine-assisted decision- } \\
\text { making, communicated globally } \\
\text { for several remote facilities. } \\
\text { Suitable for global-scale } \\
\text { industries that require fast and } \\
\text { accurate information. }\end{array}$ & $\begin{array}{l}\text { Machine-assisted decision-making, } \\
\text { but data and information only } \\
\text { required locally. Suitable for } \\
\text { industries that have centralized } \\
\text { facilities and have a high degree of } \\
\text { confidentiality so that any } \\
\text { information is only shared locally. }\end{array}$ \\
\hline $\begin{array}{l}\text { Without } \\
\text { AI/ML }\end{array}$ & $\begin{array}{l}\text { Decision-making is } \\
\text { carried out using only } \\
\text { human intelligence, } \\
\text { suitable for simple } \\
\text { systems. }\end{array}$ & $\begin{array}{l}\text { Decision-making is carried out } \\
\text { using only human intelligence } \\
\text { but is communicated remotely } \\
\text { via the internet network. This } \\
\text { system demands the } \\
\text { consistency of humans as } \\
\text { decision-makers. }\end{array}$ & $\begin{array}{l}\text { Decision-making is carried out } \\
\text { using only human intelligence and } \\
\text { is communicated to the local team. } \\
\text { this system is suitable for small- } \\
\text { scale micro industries. This system } \\
\text { requires very few resources. }\end{array}$ \\
\hline
\end{tabular}


Table 6. Research map of predictive maintenance in SCADA based industries

\begin{tabular}{|c|c|c|c|c|c|c|c|c|c|c|c|c|c|c|c|}
\hline \multirow{3}{*}{ Learning Style } & \multirow{3}{*}{ Algorithm Class } & \multirow{3}{*}{ Algorithm Name } & \multicolumn{4}{|c|}{ Electricity, gas, steam and air } & \multicolumn{4}{|c|}{ Manufacturing } & \multicolumn{4}{|c|}{ Mining and quarrying } & \multirow[b]{3}{*}{ Total } \\
\hline & & & \multicolumn{2}{|c|}{ Without Al/ML } & \multicolumn{2}{|c|}{ With AI/ML } & \multicolumn{2}{|c|}{ Without AI/ML } & \multicolumn{2}{|c|}{ With AI/ML } & \multicolumn{2}{|c|}{ Without AI/ML } & \multicolumn{2}{|c|}{ With AI/ML } & \\
\hline & & & $\begin{array}{c}\text { Without } \\
\text { IOT }\end{array}$ & With IOT & $\begin{array}{c}\text { Without } \\
\text { IOT }\end{array}$ & With IOT & $\begin{array}{c}\text { Without } \\
\text { IOT }\end{array}$ & With IOT & \begin{tabular}{c|}
$\begin{array}{c}\text { Without } \\
\text { IOT }\end{array}$ \\
\end{tabular} & With IOT & $\begin{array}{c}\text { Without } \\
\text { IOT }\end{array}$ & With IOT & $\begin{array}{c}\text { Without } \\
\text { IOT }\end{array}$ & With IOT & \\
\hline \multirow[t]{29}{*}{ Supervised } & \multirow[t]{7}{*}{ Regression } & Liniar & & & 1 & 2 & & & & & & & 1 & & 4 \\
\hline & & Polynomial & & & & & & & & & & & & & \\
\hline & & Logistic & & & & & & & & & & & & & \\
\hline & & Stepwise & & & & & & & & & & & & & \\
\hline & & $\begin{array}{l}\text { Ordinary least squares regression } \\
\text { (OLSR) }\end{array}$ & & & & & & & & & & & & & \\
\hline & & $\begin{array}{l}\text { Locally estimated scatterplot } \\
\text { smoothing (LOESS) }\end{array}$ & & & & & & & & & & & & & \\
\hline & & $\begin{array}{l}\text { Multivariate adaptive regression } \\
\text { splines (MARS) }\end{array}$ & & & & & & & & & & & & & \\
\hline & \multirow[t]{11}{*}{ Classification } & K-nearest neighbor (KNN) & & & & & & & & & & & & & \\
\hline & & Trees & & & & & & & & & & & & & \\
\hline & & Naïve bayesian & & & & & & & & & & & & & \\
\hline & & Learning vector quantization (LVQ) & & & & & & & & & & & & & \\
\hline & & Self organizing map (SOM) & & & & & & & & & & & & & \\
\hline & & locally weighted learning (LWL) & & & & & & & & & & & & & \\
\hline & & Labelling Drifts & & & & & & & & & & & & & \\
\hline & & Ripper & & & 2 & & & & & & & & & & 2 \\
\hline & & rule based classification & & & 1 & & & & & 1 & & & & & 2 \\
\hline & & support vector machine (SVM) & & & 1 & & & & & & & & & & 1 \\
\hline & & SVM and decision tree classifiers & & & 1 & & & & & & & & & & 1 \\
\hline & \multirow[t]{5}{*}{ Decision trees } & Decision trees & & & & & & & & & & & & & \\
\hline & & Random forests & & & & & & & & & & & & & \\
\hline & & $\begin{array}{l}\text { Classification and regression tree } \\
\text { (CART) }\end{array}$ & & & & & & & & & & & & & \\
\hline & & Iterative Dischotomiser 3(ID3) & & & & & & & & & & & & & \\
\hline & & $\begin{array}{l}\text { Chi-squared automatic interaction } \\
\text { detection (CHAID) }\end{array}$ & & & & & & & & & & & & & \\
\hline & \multirow[t]{6}{*}{ Bayesian networks } & Naïve Bayes & & & & & & & & & & & & & \\
\hline & & Gaussian & & & & & & & & & & & & & \\
\hline & & Multinomial & & & & & & & & & & & & & \\
\hline & & $\begin{array}{l}\text { Averaged one-dependence estimators } \\
\text { (AODE) }\end{array}$ & & & & & & & & & & & & & \\
\hline & & Bayesian belief network (BBN) & & & & & & & & & & & & & \\
\hline & & bayesian network (BN) & & & & & & & & & & & & & \\
\hline
\end{tabular}


Table 6. Research map of predictive maintenance in SCADA based industries (cont.)

\begin{tabular}{|c|c|c|c|c|c|c|c|c|c|c|c|c|c|c|c|}
\hline \multirow{3}{*}{ Learning Style } & \multirow{3}{*}{ Algorithm Class } & \multirow{3}{*}{ Algorithm Name } & \multicolumn{4}{|c|}{ Electricity, gas, steam and air } & \multicolumn{4}{|c|}{ Manufacturing } & \multicolumn{4}{|c|}{ Mining and quarrying } & \multirow{3}{*}{ Total } \\
\hline & & & \multicolumn{2}{|c|}{ Without $\mathrm{Al} / \mathrm{ML}$} & \multicolumn{2}{|c|}{ With Al/ML } & \multicolumn{2}{|c|}{ Without Al/ML } & \multicolumn{2}{|c|}{ With Al/ML } & \multicolumn{2}{|c|}{ Without Al/ML } & \multicolumn{2}{|c|}{ With Al/ML } & \\
\hline & & & $\begin{array}{c}\text { Without } \\
\text { IOT }\end{array}$ & With IOT & $\begin{array}{c}\text { Without } \\
\text { IOT }\end{array}$ & With IOT & \begin{tabular}{|c|}
$\begin{array}{c}\text { Without } \\
\text { IOT }\end{array}$ \\
\end{tabular} & With IOT & \begin{tabular}{|c|}
$\begin{array}{c}\text { Without } \\
\text { IOT }\end{array}$ \\
\end{tabular} & With IOT & \begin{tabular}{|c|}
$\begin{array}{c}\text { Without } \\
\text { IOT }\end{array}$ \\
\end{tabular} & With IOT & $\begin{array}{c}\text { Without } \\
\text { IOT }\end{array}$ & With IOT & \\
\hline \multirow{5}{*}{$\begin{array}{l}\text { Supervised } \\
\text { Cont. }\end{array}$} & \multirow[t]{5}{*}{ Other } & dependency graph & & & & & & & 1 & & & & & & 1 \\
\hline & & Fuzzy logic & & & 1 & & & & & & & & & & 1 \\
\hline & & Markov chain & & & & & & & & & & & & & \\
\hline & & not specify & & & 1 & & & & & & & & & & 1 \\
\hline & & wavelet decomposition & & & 2 & & & & & & & & & & 2 \\
\hline \multirow[t]{16}{*}{ Unsupervised } & \multirow[t]{4}{*}{ Association analysis } & A priori & & & & & & & & & & & & & \\
\hline & & Association rules & & & 2 & & & & & & & & & & 2 \\
\hline & & Eclat & & & & & & & & & & & & & \\
\hline & & FP-growth & & & & & & & & & & & & & \\
\hline & \multirow[t]{4}{*}{ Clustering } & K-mean & & & & & & & & & & & & & 0 \\
\hline & & Hierarchical clustering & & & & & & & & & & & & & \\
\hline & & expectation maximization (EM) & & & & & & & & & & & & & \\
\hline & & \begin{tabular}{|l|} 
Density-based clustering \\
\end{tabular} & & & & & & & & & & & & & \\
\hline & \multirow[t]{3}{*}{ Dimensionality reduction } & Principal component analysis (PCA) & & & & & & & & & & & & & \\
\hline & & Discriminant analysis & & & & & & & & & & & & & \\
\hline & & Multi-dimensional scaling (MDS) & & & & & & & & & & & & & \\
\hline & \multirow[t]{4}{*}{ Artificial neural network } & Perceptron & & & & & & & & & & & & & \\
\hline & & Back propagation & & & & & & & & & & & & & \\
\hline & & Radial basis function network (RBFN) & & & & & & & & & & & & & \\
\hline & & Neural Network & & & 2 & & & & & & & & & 2 & 4 \\
\hline & Combinate & Neural Network \& K-means & & & 1 & & & & & & & & & & 1 \\
\hline Combinate & $\begin{array}{l}\text { Bayesian network and } \\
\text { Artificial neural network }\end{array}$ & $\begin{array}{l}\text { Naïve Bayes classifier and Neural } \\
\text { Network }\end{array}$ & & & 1 & & & & & & & & & & 1 \\
\hline \multirow[t]{4}{*}{ not specify } & \multirow[t]{4}{*}{ not specify } & fatigue counter & 1 & & & & & & & & & & & & 1 \\
\hline & & spectral kurtosis filtering, & 1 & & & & & & & & & & & & 1 \\
\hline & & temperature graph & 1 & & & & & & & & & & & & 1 \\
\hline & & not specify & 1 & & & & & & & & & & & & 1 \\
\hline & & Grand Total & 4 & 0 & 16 & 2 & 0 & 0 & 1 & 1 & 0 & 0 & 1 & 2 & 27 \\
\hline
\end{tabular}




\section{ACKNOWLEDGEMENTS}

This research is partially supported by Hibah Penelitian Tesis Magister from the Ministry of Research and Technology/National Agency for Research and Innovation, Republic of Indonesia. The authors also acknowledge the support from Universitas Atma Jaya Yogyakarta.

\section{REFERENCES}

Ajami, H. \& Gosine, A. (2015). Migrating to digital bus technology. Water/Wastewater and Automatic Controls Symposium 2015 (WWAC 2015), 1, 21-24.

Al-Sahaf, H., Bi, Y., Chen, Q., Lensen, A., Mei, Y., Sun, Y., Tran, B., Xue, B., Zhang, M. (2019). A Survey on Evolutionary Machine Learning. Journal of The Royal Society of New Zealand, 49(2), 205-228.

Al-Turjman, F. (2017). Cognitive Sensors and IoT Architecture, Deployment, and Data Delivery. CRC Press, Inc: New York.

Bangalore, P. \& Tjernberg, L. (2013). An approach for self evolving neural network based algorithm for fault prognosis in wind turbine. 2013 IEEE Grenoble Conference PowerTech (POWERTECH 2013), art. no. 6652218 .

Bangalore, P. \& Tjernberg, L. (2015). An artificial neural network approach for early fault detection of gearbox bearings. IEEE Transactions on Smart Grid, 6(2), 980-987.

Berardis, S. \& Donisi, D. (2018). Real-time structural health monitoring system of osmangazi bridge (Turkey). IABSE Conference, Copenhagen 2018: Engineering the Past, to Meet the Needs of the Future - Report, 423-430.

Besterfield, D. H., 2013. Quality Improvement. $9^{\text {th }}$ ed. Pearson Education Inc.

Boyer, S. A., 2004. Supervisory Control and Data Acquisition. The Instrumentation, System, and Automation Society.

Carter, C. (2006). Record collection. Engineer, 293(7704), 41-42.

Carter, C. (2008). Save and prosper. Engineer, 293(7756), 62-66.

Colone, L., Dimitrov, N. \& Straub, D. (2019) Predictive repair scheduling of wind turbine drive-train components based on machine learning. Wind Energy, 22(9), 1230-1242.

De La Hermosa González-Carrato, R., Márquez, F. \& Papaelias, M. (2013). Use of novel algorithms for Predictive Maintenance in wind turbines. 10th International Conference on Condition Monitoring and Machinery Failure Prevention Technologies
(CM 2013 and MFPT 2013), 310-322.

De La Hermosa Gonzalez-Carrato, R.R., Márquez, F.P.G., Pérez, J.M.P., Papaelias, M., Entezami, M. (2012). A novel predictive maintenance method for wind turbines based on wavelets transforms. 9th International Conference on Condition Monitoring and Machinery Failure Prevention Technologies (CM and MFPT 2012), 15-27.

Gigoni, L., Betti, A., Tucci, M. \& Crisostomi, E., (2019). A Scalable Predictive Maintenance Model for Detecting Wind Turbine Component Failures Based on SCADA. IEEE Power and Energy Society General Meeting, 8973898.

Godwin, J. \& Matthews, P. (2013). Classification and detection of wind turbine pitch faults through SCADA data analysis. International Journal of Prognostics and Health Management, 4(S2). art. no. 16

Godwin, J., Matthews, P. \& Watson, C. (2013). Classification and detection of electrical control system faults through SCADA data analysis. Chemical Engineering Transactions, 33, 985-990.

Gonzalez, D., Zatica, U., Gallastegi, A. \& Cormenzana, M. (2014). Diagnosis of capacitive voltage transformers in service New method to determine the accuracy of CVTs while in service, without physical references and with a light portable unit. CIGRE Session 45 - 45th International Conference on Large High Voltage Electric Systems.

Grosch, R. \& Bilot, P. (2002). A simple strategy for integrated plant management and control. ISA Instrumentation, Systems, and Automation Conference Proceedings, 13-23.

Hagner, S. \& Bujak, J. (2016). Optimizing the network and the asset lifecycle and reducing operational and capital costs through predictive analytics and asset health management. CIGRE Session 46.

Hwang, K. \& Chen, M. (2017). Big-Data Analytics for Cloud, IoT and Cognitive Computing. John Wiley \& Sons. The UK.

Ignat, S., Stancel, E. \& Stoian, I. (2012). Support for condition based maintenance: Operating equipment performances monitoring. IEEE International Conference on Automation, Quality and Testing, Robotics, AQTR 2012 - Proceedings, 234-239.

Khatib, A.-R., Dong, X., Qiu, B. \& Liu, Y. (2000). Thoughts on future internet based power system information network architecture. Proceedings of the IEEE Power Engineering Society Transmission and Distribution Conference, 155-160. 
Kiangala, K. \& Wang, Z. (2018). Initiating predictive maintenance for a conveyor motor in a bottling plant using industry 4.0 concepts. International Journal of Advanced Manufacturing Technology, 97(9-12), 3251-3271.

Leahy, K., Gallagher, C., O'Donovan, P., Bruton, K., O'Sullivan, D.T.J. (2018). A robust prescriptive framework and performance metric for diagnosing and predicting wind turbine faults based on SCADA and alarms data with case study. Energies, 11(7), 1738 .

Lebranchu, A., Charbonnier, S., Bérenguer, C. \& Prevost, F. (2015). Review and analysis of SCADA data-based methods for health monitoring of wind turbines. Europe, Safety and Reliability of Complex Engineered Systems - Proceedings of the 25th European Safety and Reliability Conference, ESREL 2015, 2413-2421.

Lebranchu, A., Charbonnier, S., Berenguer, C. \& Prevost, F. (2016). Using SCADA data for fault detection in wind turbines: Local internal model versus distance to a wind farm reference. Applied Condition Monitoring, 4, 225-236.

Liker, J. K. \& Meier, D. (2006). The Toyota Way Fieldbook. McGraw-Hill. USA

Mazur, D., Kay, J. \& Mazur, K. (2014). Advancements in vibration monitoring for the mining industry. IEEE Industry Application Society Annual Meeting, IAS, 6978459.

Mobley, R. K. (2002). An Introduction to Predictive Maintenance. Butterworth-Heinemann, USA.

Moleda, M., Momot, A. \& Mrozek, D. (2020). Predictive Maintenance of Boiler Feed Water Pumps. Sensors, 20(2), 571.

Montague, J. (2015). Joining forces. Control, 28(9), 3239.

NASA (2000). Reliability Centered Maintenance Guide for Facilities and Collateral Equipment. National Aeronautics and Space Administration, Washington DC.

Nisi, M., Renga, D., Apiletti, D., Giordano, D., Huang, T., Zhang, Y., Mellia, M., Baralis, E. (2019). Transparently mining data from a medium-voltage distribution network: A prognostic-diagnostic analysis. Lisbon, Portugal, CEUR Workshop Proceedings, 2322.

Nuñez, J., Pina, I.F.B., Martínez, A.R., Pérez, S.D., Oliveira, D.L. (2019). Tools for the Implementation of a SCADA System in a Desalination Process. IEEE Latin America Transactions, 17(11), 1858-1864.
Olivencia Polo, F., Alonso Del Rosario, J. \& Cerruela García, G. (2010). Supervisory control and automatic failure detection in grid-connected photovoltaic systems. Lecture Notes in Computer Science, 6096, 458-467.

Perez, E. (2010). Fatigue counters for predictive maintenance. European Wind Energy Conference and Exhibition, 5, 3999-4009.

Renga, D., Apiletti, D., Giordano, D., Nisi, M., Huang, T., Zhang, Y., Mellia, M., Baralis, E. (2020). Datadriven exploratory models of an electric distribution. Computing. 102(5), 1199-1211.

Rensburg, N. (2019a). Usage of artificial intelligence to reduce operational disruptions of ESPs by implementing predictive maintenance. Society of Petroleum Engineers - Abu Dhabi International Petroleum Exhibition and Conference.

Rensburg, N. (2019b). Autonomous well surveillance for ESP pumps using artificial intelligence. Society of Petroleum Engineers - SPE Oil and Gas India Conference and Exhibition.

Richard, E. (2015). Getting the most from your SCADA data. Water/Wastewater and Automatic Controls Symposium, 185-193.

Sánchez, L. \& Couso, I. (2012). Singular spectral analysis of ill-known signals and its application to predictive maintenance of windmills with SCADA records. Soft Computing, 16(5), 755-768.

Schafer, K. (2000). Preventive maintenance plan optimized through automation. Part 2. Data acquisition, trend analysis systems should be integrated with program via computer. Pipe Line and Gas Industry, 83(2), 53-56.

Shalev-Shwartz, S. \& Ben-David, S. (2014). Understanding Machine Learning From Theory to Algorithms. Cambridge University, USA.

Singh, A., Bapat, J. \& Das, D. (2013). Distributed health monitoring system for control in Smart Grid network. IEEE Innovative Smart Grid Technologies Asia, ISGT Asia, 6698765.

Stetco, A., Dinmohammadi, F., Zhao, X., Robu, V., Flynn, D., Barnes, M., Keane, J., Nenadic, G. (2018). Machine Learning Methods for Wind Turbine Condition Monitoring: A Review. Renewable Energy, 133, 620-635.

Suryadarma, E.H.E., Ai, T.J. \& Nugraha, B.B. (2020). Predictive Maintenance of Cooling System in Casting Process by Data SCADA. International Journal of Advanced Science and Technology, 29, 3555-3561. 
Tautz-Weinert, J. \& Watson, S. (2017). Using SCADA data for wind turbine condition monitoring - A review. IET Renewable Power Generation, 11(4), 382-394.

Tinham, B. (2008). Peak performance. Plant engineer London, 52(MAY/JUNE), 19-21.

Toporek, D. \& Hutchings, A. (2011). Making fault data and non-SCADA data accessible for predictive analysis in data historians. IEEE Power and Energy Society General Meeting, 6039731.

UN (2008). International standard industrial classification of all economic activities revision 4.4 ed. United Nations Publication, New York.

Wang, J., Liu, C., Zhu, M., Guo, P., Hu, Y. (2018). Sensor Data Based System-Level Anomaly Prediction for Smart Manufacturing. Proceedings 2018 IEEE International Congress on Big Data, BigData Congress, 158-165.

Waterbury, B. (2001). Is now the time for your plant to invest in automation and control? Control, 14(5), 4047.

Zhao, W., Siegel, D. \& Lee, J. S. L. (2013). An integrated framework of drivetrain degradation assessment and fault localization for offshore wind turbines. International Journal of Prognostics and Health Management, 4(46).

Zhao, Y., Li, D., Dong, A., Kang, D., Lv, Q., Shang, L. (2017). Fault prediction and diagnosis of wind turbine generators using SCADA data. Energies, 10(8), 1-17. 